\title{
Junior doctors may strike in the UK
}

${ }^{6} \mathrm{~S}$ ave our contract, save our patients, save our NHS." So chanted thousands of medical students and young physicians in London on Sept. 28 as they protested the new contract offered to England's 50000 junior doctors. Junior doctors, the equivalent of North American residents, are now considering strike action.

At issue are changes to pay rates and conditions that junior doctors say devalue weekend and evening work. The National Health Service (NHS) pays more for hours deemed "antisocial" (currently after 7 pm and during weekends). Under the proposed contract, the "antisocial" hours will begin at 10 pm and Saturdays would be exempt.

The new contract is part of ongoing NHS reforms, dubbed 7-day care, as discussed by Secretary of State for Health Jeremy Hunt in July. He said newly qualified hospital doctors, such as junior doctors, will not be able to opt out of weekend and evening hours. Doctors already on contract will not be forced into new ones, but Hunt said he expects "the majority of hospital doctors to be on 7-day contracts" before the next election. Junior doctors in Scotland and Wales are still under contract and are not affected.

At the demonstration, medical student Harriet Pearce said, "Being a doctor should not be a game of who has got the most stamina." Doctor-in-training Zachary Ferguson added, "If it puts our health at risk, it puts our patients' health at risk." He pointed out that "I've just done three nights in a row. I love my job and I don't want to leave the NHS but we should be paid fairly."

Junior doctors will vote on industrial action, but as of now there is no date set for either the vote or the strike.

More than issues of pay and hours, the British Medical Association (BMA), the union representing doctors and medical students, objects to the government's threat to impose the new con-

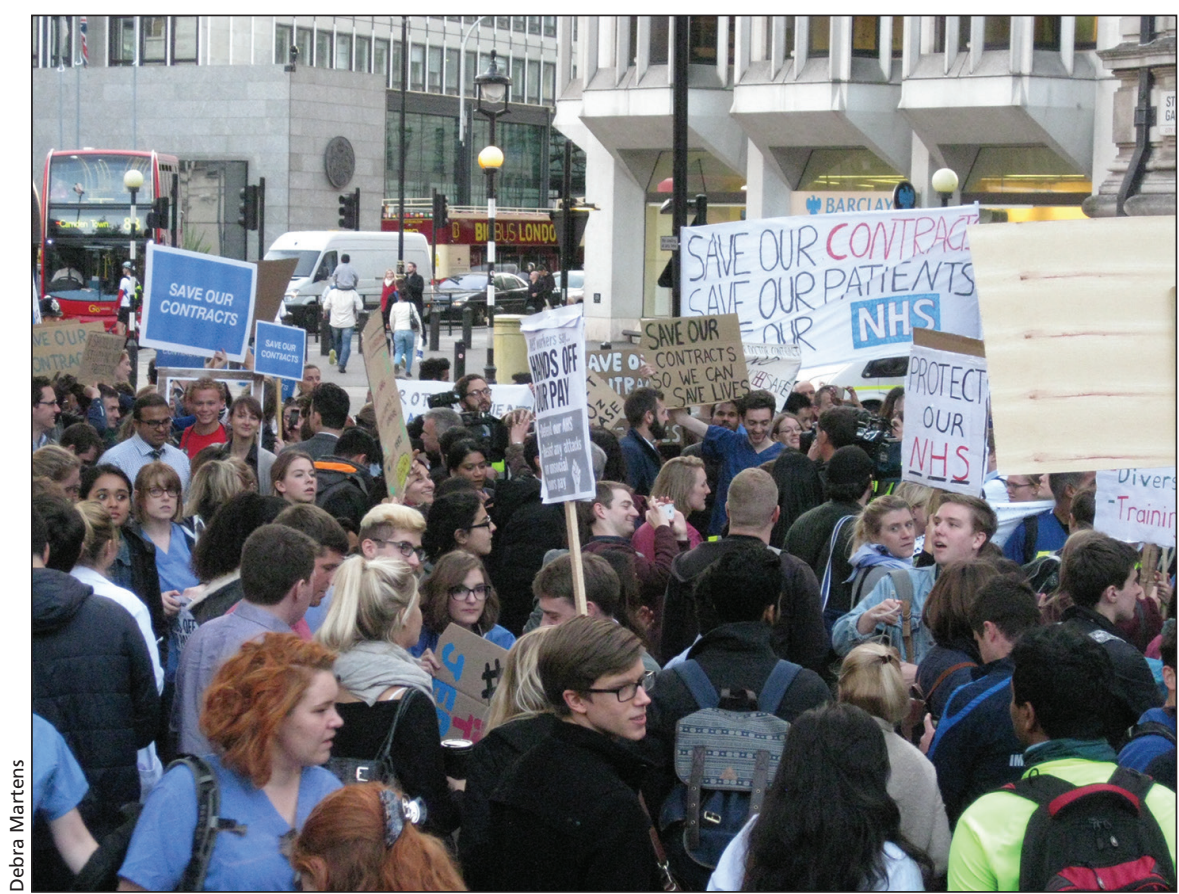

Doctors and trainees protested a new contract for junior doctors, saying it devalues their work.

tract. A BMA spokesperson stressed that before the junior doctors committee returns to the negotiating table, the threat of imposition must be removed. In addition, the BMA wants proper recognition of antisocial hours as premium time, no disadvantage for those working antisocial hours compared to the current system, no disadvantage for those working less than full time as compared to current pay banding, pay for all work done, and proper hours that protect patients and their doctors.

According to a BMA media advisor, the new rates of pay would mean, for example, a cut of one-third to salaries of general practitioners in training.

The Department of Health maintains there will not be a cut to the overall pay of junior doctors and that their hours will be safeguarded. An NHS press officer dismissed "misconceptions" about what the contract would look like, saying that the details have not been established and can't be established until junior doctors come back to the table. The possibility of strike action has not changed the NHS position: they want to negotiate the contract with junior doctors, she said. However, if junior doctors don't negotiate, "then we will implement a contract."

With neither side willing to commit to a deadline, it seems the junior doctors' contract is at an impasse. Meanwhile, the Royal College of General Practitioners, which rarely comments on contracts, started a petition demanding, in part, "that any new contract for junior doctors will not have a detrimental effect on pay and conditions of medical graduates choosing general practice." The petition has garnered over 300000 signatures.

In a Sept. 26 press release, the BMA interpreted an increase in applications to work abroad as proof that the new junior doctors' contract may cost the NHS that which it wishes to regulate: doctors. Debra Martens, London, UK

CMAJ 2015. DOI:10.1503/cmaj.109-5174 